\title{
FASHION REVOLUTION COMO MOVIMENTO AMBIENTALISTA DE JUSTIÇA AMBIENTAL: UMA ANÁLISE SOB A ÓTICA DO DIREITO AO AMBIENTE ECOLOGICAMENTE EQUILIBRADO
}

\author{
Vanessa de Mello Seibel ${ }^{125}$ \\ Isabel Christine Silva de Gregory ${ }^{126}$
}

Recebido em: 15/10/2019

Aprovado em: 06/02/2020

\section{RESUMO}

O presente estudo tem por objetivo analisar a possibilidade de identificação do movimento Fashion Revolution como um movimento ambientalista de justiça ambiental e social. Desse modo, busca-se apresentar e caracterizar os movimentos ambientalistas de justiça ambiental e social, tendo em vista o direito ao ambiente ecologicamente equilibrado. Ainda, analisa-se a possibilidade de identificação do movimento Fashion Revolution como movimento ambientalista de justiça ambiental e social e, assim, um gerador de contracultura também na indústria da moda. Como teoria de base, será empregada a matriz epistemológica pragmático-sistêmica, a qual permite um enfoque interdisciplinar acerca da caracterização do movimento do Fashion Revolution como movimento ambientalista de justiça ambiental e social, a partir da análise das características e temas principais dos movimentos ambientalistas. Com o presente estudo foi possível concluir que o movimento Fashion Revolution pode ser indicado como um movimento ambientalista de justiça ambiental e social, conforme as características e os principais temas de movimento ambientalista.

Palavras-chave: Movimento ambiental. Justiça. Fashion Revolution. Direito. Ambiente equilibrado.

\section{INTRODUÇÃO}

\footnotetext{
${ }^{125}$ Mestranda do Programa de Pós-Graduação em Direito (PPGD). Possui especialização em Direito Constitucional Aplicado pelo Complexo Damásio de Jesus. Advogada.

${ }^{126}$ Doutora em Desenvolvimento Regional pela Universidade de Santa Cruz do Sul - UNISC (2007). Professora do Programa de Pós- Graduação Stricto Sensu da Universidade Federal de Santa Maria (UFSM).
} 
Os movimentos ambientalistas de justiça ambiental nascidos nos anos 60 foram inspiração para a promoção de uma contracultura de preservação ambiental. Com efeito, o papel exercido pelos movimentos ambientalistas de justiça ambiental e social de reafirmar o valor da vida em todas as suas manifestações, em face dos interesses econômicos, conquista participantes e engaja cada vez mais toda a sociedade de diferentes formas.

A promoção de conhecimento no ciberespaço e a grande participação dos consumidores nas redes sociais, provocaram mudanças também na indústria da moda, a qual optou, de modo geral, pelo modelo de produção capitalista de fast fashion (moda rápida), em vista de uma sociedade de consumo.

Isso porque a adoção o modelo de produção chamado fast fashion (moda rápida), o qual tem processo de produção de apenas três semanas, com estímulo ao consumo através de promoções e modelos limitados, bem como com rápido descarte dos produtos pela baixa qualidade, está associado ao crescimento dos impactos ambientais e sociais da indústria da moda.

Em virtude da busca incessante para satisfazer os interesses econômicos, tem-se os desastres ambientais e sociais, em tempos em que o lucro prevalece em relação à própria vida humana. Há números alarmantes acerca dos resíduos têxteis descartados no meio ambiente e há denúncias reiteradas da submissão dos trabalhadores dessa indústria à condições de trabalho deploráveis, associadas à escravidão moderna.

Assim, a sociedade com mais acesso a informação acerca dos danos ambientais causados e, a partir de eventos trágicos, passou a exigir mudanças na indústria da moda, dando origem ao movimento Fashion Revolution. Com efeito, a existência de um movimento ambientalista, que busca a transparência com introdução de medidas de sustentabilidade na cadeia têxtil e valorização do trabalhador, pode representar mudanças também na maneira que se consome moda e promover o direito ao meio ambiente ecologicamente equilibrado.

Nesse cenário, questiona-se em que medida o movimento Fashion Revolution pode ser caracterizado como movimento ambientalista de justiça ambiental, tendo em vista o direito ao ambiente ecologicamente equilibrado? Para responder esse questionamento, o presente estudo tem por objetivo analisar a possibilidade de identificação do movimento Fashion Revolution como um movimento ambientalista de justiça ambiental e social. Desse modo, busca-se apresentar e caracterizar os movimentos ambientalistas de justiça ambiental e social. Ainda, analisa-se a 
possibilidade de identificação do movimento Fashion Revolution como movimento ambientalista de justiça ambiental e social e, assim, um gerador de contracultura também na indústria da moda.

Como teoria de base, será empregada a matriz epistemológica pragmático-sistêmica, a qual permite um enfoque interdisciplinar acerca da caracterização do movimento do Fashion Revolution como movimento ambientalista de justiça ambiental e social, a partir da análise das características e temas principais dos movimentos ambientalistas.

O estudo utilizará como método de abordagem, o método dedutivo, para caracterizar os movimentos ambientalistas de justiça ambiental e a verificar em que medida o movimento Fashion Revolution pode ser considerado movimento ambientalista de justiça ambiental e social.

Como método de procedimento específico, adotar-se-á o método de pesquisa bibliográfico, onde será realizada por meio da documentação indireta, que será efetivada com a utilização de doutrinas, artigos científicos, teses, sites oficiais, revistas científicas para caracterizar os movimentos ambientalistas e o movimento Fashion Revolution. Como técnica de pesquisa serão utilizados resumos estendidos das doutrinas, artigos científicos, teses, sites oficiais e revistas científicas.

\section{MOVIMENTOS AMBIENTALISTAS DE JUSTIÇA AMBIENTAL: BREVE ANÁLISE}

O movimento ambientalista multifacetado surgiu a partir dos anos 60 na maior parte do mundo, especialmente, nos Estados Unidos e no norte da Europa, está relacionado em grande medida com o núcleo de uma reversão de pensamento em relação à economia, sociedade e natureza, propiciando o surgimento de uma nova cultura (CASTELLS, 2018).

No final de 70, diversos ecologistas radicais, liderados por David Foreman, fundaram nos Estados Unidos do Novo México e Arizona o Earth First! - movimento extremista partidário da insubordinação civil, praticando, inclusive, atos de sabotagem, contra construção de barragens, extração de madeira e outras formas de agressão à natureza (CASTELLS, 2018).

Em seguida, no início dos anos 80, a preservação da natureza tem com ponto em comum, que une as organizações ambientalistas que atuam nesse sentido que é a defesa pragmática das causas voltadas a preservação da natureza mediante o sistema institucional. Nesse sentido, os movimentos ambientalistas filiaram-se à partidos políticos ou organizaram os seus visando o seu 
ingresso no âmago do Estado e inserir de "dentro para fora" as transformações em prol do meio ambiente (CASTELLS, 2018).

Atualmente, a temática ambiental encontra suporte na Constituição Federal de $1988^{127}$, onde versa sobre a proteção do meio ambiente, sendo o meio ambiente fundamental para que haja uma qualidade de vida digna. Esse direito encontra-se alicerçado no artigo 225 do diploma constitucional:

Art. 225. Todos têm direito ao meio ambiente ecologicamente equilibrado, bem de uso comum do povo e essencial à sadia qualidade de vida, impondo-se ao poder público e à coletividade o dever de defende-lo e preservá-lo para as presentes e futuras gerações

Nesse prisma, pode-se afirmar que as preocupações referentes ao meio ambiente vêm se alargando de forma progressiva nos últimos anos, contudo, o desenvolvimento econômico oriundo do processo de globalização contribui para a atual crise ambiental (ARAÚJO; TYBUSCH, 2013).

O movimento ambientalista não pode ser considerado único, tendo em vista que as suas ações coletivas, políticas e discursos ambientalistas são bastante diversificados. Desse modo, fazse necessário indicar que ambientalismo pode ser conceituado como "todas as formas de comportamento coletivo que, tanto em seus discursos como em sua prática, visam corrigir formas destrutivas de relacionamento entre o homem e seu ambiente natural, contrariando a lógica estrutural e institucional atualmente predominante" (CASTELLS, 2018, p. 225). Ainda, com relação ao ambientalismo, importante definir que os movimentos sociais se caracterizam por três elementos constitutivos: identidade, adversário e objetivo (CASTELLS, 2018).

Nesse cenário, a mobilização das comunidades locais em defesa de seu espaço mostra-se a forma de ação ambiental que mais se destaca ultimamente, tendo em vista a proximidade da relação das pessoas com as questões de degradação ambiental. Contudo, é preciso ressaltar que embora o movimento seja local, não é necessariamente localista, eis que visam assegurar qualidade de vida com resistência interesses burocráticos (CASTELLS, 2018).

O movimento ambientalista possui quatro temas principais. Primeiro tema é a relação estreita e ambígua com a ciência e tecnologia, eis que ao mesmo tempo em que há uma descrença sobre os benefícios da evolução tecnológica, o próprio movimento ambiental se vale das

\footnotetext{
${ }^{127}$ Importa destacar que, no Brasil, a proteção jurídica atribuída ao meio ambiente não se iniciou com a Carta Magna de 1988. Apesar da existência anterior de leis esparsas, podemos apontar como marco dessa proteção a edição, em 31 de agosto de 1981, da Lei $n^{\circ}$ 6.938, que foi recepcionada pela atual Constituição com status de Lei Complementar, estabelecendo a proteção do meio ambiente em território brasileiro (BEZERRA, 2019).
} 
tecnologias para exercer suas ações. O segundo tema é o ambientalismo como um movimento com base na ciência, uma vez que o tem por objetivo reassumir o controle social sobre os produtos da mente humana antes que a ciência e tecnologia adquiram vida própria e se imponham contra nós e a natureza (CASTELLS, 2018).

Ainda, o terceiro tema são os conflitos sobre a transformação estrutural são sinônimos das lutas pela redefinição histórica das duas expressões fundamentais e materiais da sociedade: o tempo e o espaço. Em relação a esse tema tem-se que a democracia de bases populares é o modelo político implícito na maioria dos movimentos ambientalistas (CASTELLS, 2018).

O quarto tema é o controle sobre o tempo está no jogo na sociedade em rede, e o movimento ambientalista é provavelmente o protagonista do projeto de uma temporalidade nova e revolucionária. $\mathrm{O}$ embate histórico pela temporalidade ocorre entre a aniquilação do conceito de tempo no fluxo recorrente da rede de computadores e a realização do tempo glacial ${ }^{128}$ mediante a incorporação consciente do nosso eu cosmológico (CASTELLS, 2018).

Ainda, indica-se que o movimento ambientalista deve boa parte do seu sucesso ao fato demonstrar notável capacidade de adaptação às condições de comunicação e mobilização apresentadas pelo novo paradigma tecnológico (CASTELLS, 2018).

No que se refere à ideia justiça, Amartya Sen, utiliza os conceitos das palavaras niti e nyaya, de origem sânscrita e ligadas à ideia de justiça. Niti é a justiça que deriva do cumprimento estrito dos costumes e dos deveres contidos na lei. Já nyaya aponta para uma avaliação consequencialista, em que os resultados de um ato estão ligados à sua própria justiça. A partir disso, busca uma teoria de justiça que seja capaz de orientar uma reflexão que estimule um engajamento efetivo das pessoas não apenas no cumprimento das leis, mas na transformação da sociedade para que ela se torne mais próxima da própria justiça, ao menos com uma exclusão das injustiças sentidas em um determinado momento como inaceitáveis (SEN, 2011).

Com efeito, a noção de justiça ambiental engloba o direito a um ambiente seguro, sadio e preditivo para todos, onde o "meio ambiente" é considerado em sua totalidade, incluindo suas dimensões ecológicas, físicas construídas, sociais, políticas, estéticas e econômicas. Assim, é possível indicar como exemplo de noção de justiça o direito de todo trabalhador a um meio

\footnotetext{
${ }^{128}$ Segundo Manuel Castells, há uma concepção de tempo chamado tempo glacial. Com base na fórmula de Lash e Urry, a noção de tempo glacial significa "a relação entre homem e a natureza é um processo evolucionário e de longo prazo. Tal relaçã se projeta para trás na história imediata da humanidade e pra a frente em direção a um fututro totalmente não especificado"(CASTELLS, 2018, p. 157-158).
} 
ambiente de trabalho sadio e seguro, sem que ele seja forçado a escolher entre uma vida de risco e o desemprego (ACSELRAD, MELLO e BEZERRA, 2009).

Como princípios da justiça ambiental pode-se citar, exemplificativamente, o princípio da poluição tóxica para ninguém, o qual visa reverter a lógica "sempre no quintal dos pobres e negros" e o princípio de transição justa que busca um modo para que a luta contra a poluição desigual no destrua emprego dos trabalhadores das industrias poluentes ou penalize as populações dos países menos industrializados para onde as transnacionais tenderiam a transferir suas "fábricas sujas". Ainda, a perseguição de políticas ambientais democraticamente instituídas, eis que a ausência de uma regulação efetiva sobre os grandes agentes econômicos do risco ambiental é o que possibilita que estes procurem livremente as comunidades mais carentes como vítimas preferencias de suas atividades danosas. (ACSELRAD, MELLO e BEZERRA, 2009).

Também visando a efetiva justiça ambiental e social, os movimentos ambientalistas possuem estratégias, tais como: a) produção de conhecimento próprio: participação pública, institucional e política e incluindo a consideração das dimensões sociais, culturais, econômicas e institucionais vivenciadas pelos grupos atingidos, assim como os efeitos dos empreendimentos nos modos de subjetivação e na saúde física e mental dos indivíduos e de grupo; b) pressão pelo aperfeiçoamento da legislação de proteção ambiental: dependendo da localidade, das características de sua legislação ou natureza do conflito, a pressão pela instituição de novas leis torna-se uma estratégia necessária; e c) difusão espacial do movimento: as lutas por justiça ambiental constituem uma forma de resistência organizada contra os efeitos perversos da mobilidade espacial do capital e dos esforços que os grandes interesses econômicos empreendem para instaurar diferentes padrões socioambientais para as suas atividades. (ACSELRAD, MELLO e BEZERRA, 2009).

Com efeito, a reivindicação por justiça ambiental - compreendida como tratamento justo e o envolvimento pleno dos grupos sociais, independentemente de sua origem ou renda, nas decisões sobre o acesso, a ocupação e o uso dos recursos ambientais em seus territórios - alterou a configuração de formas envolvidas nas lutas ambientais ao considerar o caráter indissociável de ambiente e sociedade politizando a questão do racismo e das desigualdades ambientais. Desse modo, a noção de justiça ambiental implica, pois, o direito a um ambiente seguro, sadio e preditivo para todos, onde o "meio ambiente" é considerado em sua totalidade, incluindo suas dimensões 
ecológicas, físicas construídas, sociais, políticas, estéticas e econômicas (ACSELRAD, MELLO e BEZERRA, 2009).

Através das lutas fundamentais sobre apropriação da ciência, tempo e espaço, os ecologistas inspiram a criação de uma nova identidade, a identidade biológica, como uma cultura da espécie humana como componente da natureza. Como adversário declarado, tem-se o nacionalismo do Estado (Estado-Nação) que tende a exercer poder sobre determinado território, comprometendo a inter-relação entre territórios e a noção de um ecossistema global compartilhado. Trata-se de uma busca por uma única identidade global proposta a todos os seres humanos independente de seus vínculos sociais, de gênero ou de religião (CASTELLS, 2018).

No contexto dos temas, princípios e estratégias dos movimentos ambientalistas de justiça ambiental e social, tem-se que o papel de reafirmar o valor da vida em todas as suas manifestações, em face dos interesses econômicos, exercido pelos movimentos ambientalistas, conquista adeptos e eleva a sua participação em toda a sociedade de diferentes formas.

Assim, no que se refere a indústria da moda, a sociedade com mais acesso a informação acerca dos danos ambientais causados e, a partir de eventos trágicos, passou a exigir mudanças, dando origem ao movimento Fashion Revolution em busca da efetivação do direito ao ambiente ecologicamente equilibrado.

\section{FASHION REVOLUTION COMO MOVIMENTO AMBIENTALISTA E O DIREITO AO AMBIENTE ECOLOGICAMENTE EQULIBRADO}

Após a Revolução Industrial, o rápido desenvolvimento e a propagação de uma sociedade de consumo, fruto do sistema capitalista, foram intensificados "com a publicidade, a moda, a mídia de massa e, principalmente, o crédito [...] com o crédito tornou-se possível satisfazer imediatamente todos os desejos" (LIPOVETSKY, 2005, p.64).

Jean Baudrillard caracteriza a sociedade de consumo como "a universalidade do faitdrivers $^{129}$ na comunicação de massa. Toda a informação política, histórica e cultural é acolhida sob

\footnotetext{
129 O dicionário Priberam apresenta o seguinte conceito: fait divers (locução francesa, de fait, ffato + divers, diverso, variado)1. Conjunto de ocorrências e acontecimentos variados e se m ligação entre eles, que correspondem a uma rubrica jornalística. 2. Fato ou assunto pouco importante.
} 
a mesma forma do fait divers, ou seja, distanciada pelos meios de comunicação e reduzida a signos" (2018, p. 25). Em seguida, o referido autor afirma ainda acerca do papel das mídias na sociedade de consumo que “ as comunicações de massa não fornecem a realidade, mas a vertigem da realidade" (BAUDRILLARD, 2018, p. 25).

Nesse contexto, surgiu movimento mundial da indústria da moda chamado fast fashion, um sistema de mercado da moda que dita quase que diariamente novas tendências, modas sazonais e produz novas coleções que alimentam o consumo desenfreado. Esse movimento surgiu em meados dos anos 90, e pode ser chamado de modo de produção capitalista em que há um padrão de produção e consumo no qual os produtos são fabricados, consumidos e descartados rapidamente (ECICLE, 2019).

O modelo de negócios depende da eficiência em fornecimento e produção em termos de custo e tempo de comercialização dos produtos ao mercado, que são a essência para orientar e atender a demanda de consumo por novos estilos a baixo custo (ECICLE, 2019).

Contudo, o modelo de produção capitalista de moda rápida, em razão da aceleração da cadeia de produção, tem severos impactos ambientais. Segundo a Forbes, a indústria da moda é a $2^{\circ}$ maior poluidora mundial e aproximadamente 70 milhões de barris de petróleo são usados a cada ano para produzir poliéster, que hoje é a fibra mais utilizada em roupas e cuja decomposição leva em torno de 200 anos (FORBES, 2019).

Somando-se a esse cenário, o desabamento do edifício Rana Plaza em Bangladesh, em 24 de abril de 2013, o qual causou mais de mil mortes de trabalhadores da indústria de confecção e deixou mais de 2.500 feridos, os quais trabalhavam para marcas globais, em condições análogas à escravidão (CALEIRO, 2019).

Nesse cenário, foi criado o movimento global Fashion Revolution com o objetivo mostrar que a mudança na indústria da moda é possível e encorajar todos aqueles que estão em busca de um futuro mais ético e sustentável para a moda. Atualmente, o movimento está presente em 100 países, entre eles o Brasil, no qual há mais de 50 cidades (ABREU, 2019).

Com o intuito de mostrar que é possível mudar esse cenário de impactos sócio ambientais e construir um futuro mais sustentável através de envolvimento e transparência no processo produtivo, o movimento Fashion Revolution tem como foco três eixos: mudança cultural, mudança na indústria e mudança política (ABREU, 2019). 
Com efeito, no que diz com o direito ao ambiente ecologicamente equilibrado, não é possível olvidar das dimensões, ecológica, econômica e, especialmente a social, na medida em que toda a discussão sobre a crise ambiental moderna, e sobre uma alternativa ambientalmente mais saudável para o desenvolvimento humano, se considera a sociedade humana como fazendo parte do meio ambiente (FOLADORI, 2019).

Nesse sentido, o movimento lançou a campanha Fashion Revolution Day, ou seja, o Dia da Revolução da Moda, que acontece todo o dia 24 de abril com o objetivo de lembrar a tragédia do Rana Plaza e o verdadeiro custo da moda. Todos os anos, ao longo da semana do dia 24 são realizadas atividades, oficinas e palestras de acordo com a programação de cada cidade, com ações voltadas a promoção de uma moda sustentável, baseada em princípios éticos e ambientais (SLOWLY, 2019).

A campanha tem como o objetivo aumentar a conscientização sobre o verdadeiro custo da moda e seu impacto em todas as fases do processo de produção e consumo, mostrando ao mundo que a mudança é possível através da celebração dos envolvidos na criação de um futuro mais sustentável e criar conexões exigindo transparência (MATTOS, 2019).

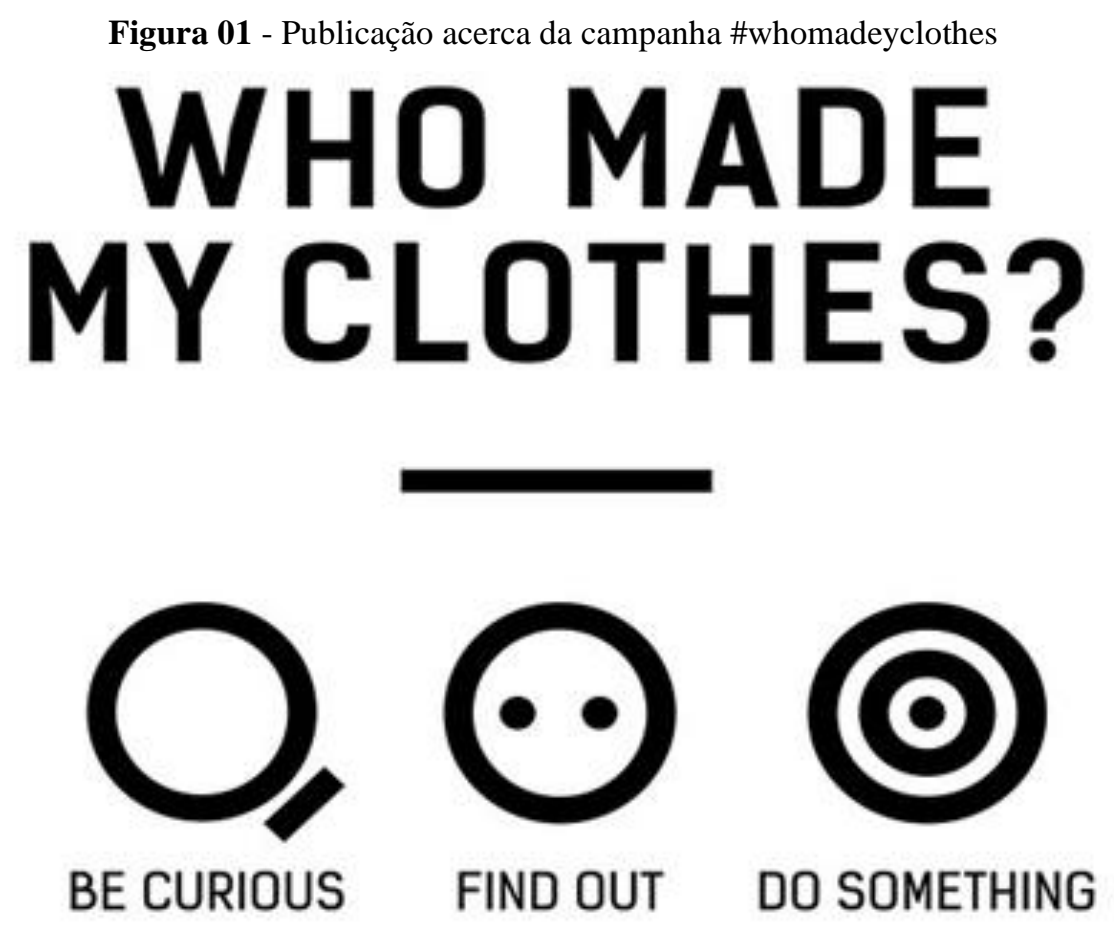

(Fonte: Blog Anita Bem Criada)

Com efeito, o movimento foi inserido em uma sociedade de consumo, na qual o acesso à 
informação a partir da popularização da internet e tecnologias de informação promoveram a participação dos consumidores no ciberespaço, os quais deixaram de ser apenas receptores de informações e passaram a produzir e compartilhar informações e conteúdo. A partir disso, Manuel Castells observou o papel das mídias nas mudanças de atitude em relação a natureza diante dos estudos científicos acerca das mudanças climáticas e, consequentemente, a mudança de atitude do mundo empresarial, para transformar a cultura da natureza (CASTELLS, 2015).

Desse modo, ao lançar o manifesto "pró-moda" nas redes sociais através da hashtag \#whomademyclothes, na tradução livre \#quemfezminhasroupas, o Fashion Revolution incentiva a transparência no mundo da moda com o fim de evitar novas tragédias como no Rana Plaza e valorizar os trabalhadores da indústria moda, bem como promover uma produção com viés sustentável (FASHION REVOLUTION, 2019). Conforme os dados divulgados pelo jornal inglês The Gardian (2019), no ano de 2018, 3, 25 milhões de pessoas participaram da campanha e lançaram a pergunta \#whomademyclothes, nas redes sociais.

Figura 02 - Publicação acerca da campanha \#whomadeyclothes

FashionRevolution @ @Fash_Rev·24 de abr

As we ask \#Whomademyclothes, @BoF reports on our just-out Fashion

Transparency Index that, "Six years after Rana Plaza, Fashion Revolution's annual transparency index shows the industry largely remains a black box"

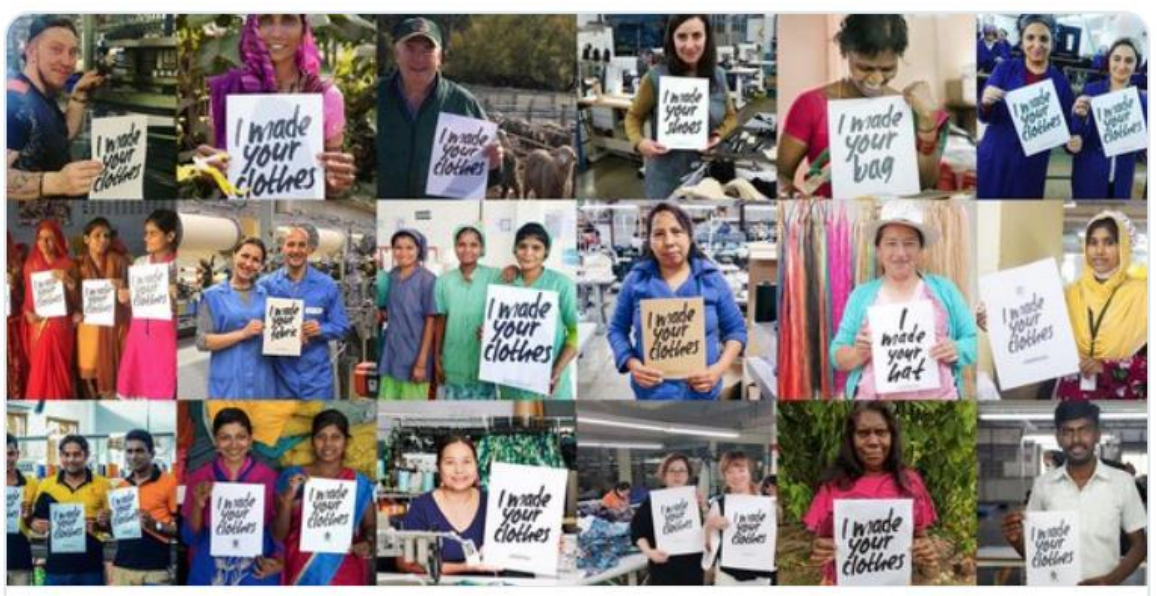

Fashion Industry Still Failing on Transparency Six years after Rana Plaza, Fashion Revolution's annual transparency index shows the industry largely remains a black box.

businessoffashion.com

$2 \quad \uparrow \downarrow 43 \quad \bigcirc 55$

(Fonte: Twitter) 
Verifica-se, assim que no contexto da transparência, o movimento se utiliza das tecnologias de informação para inserir na grande mídia informação dos problemas ambientais e sociais com o fim de promover mudanças nos hábitos de consumo da sociedade, em observância ao direito ao ambiente ecologicamente equilibrado, no contexto da globalização da natureza

O movimento Fashion Revolution, a exemplo do Greepeace, exerce a capacidade de adaptação às condições de comunicação e mobilização apresentadas pelo novo paradigma tecnológico, de modo que as suas ações ocorrem em razão de eventos que sejam apropriados para a divulgação na mídia.

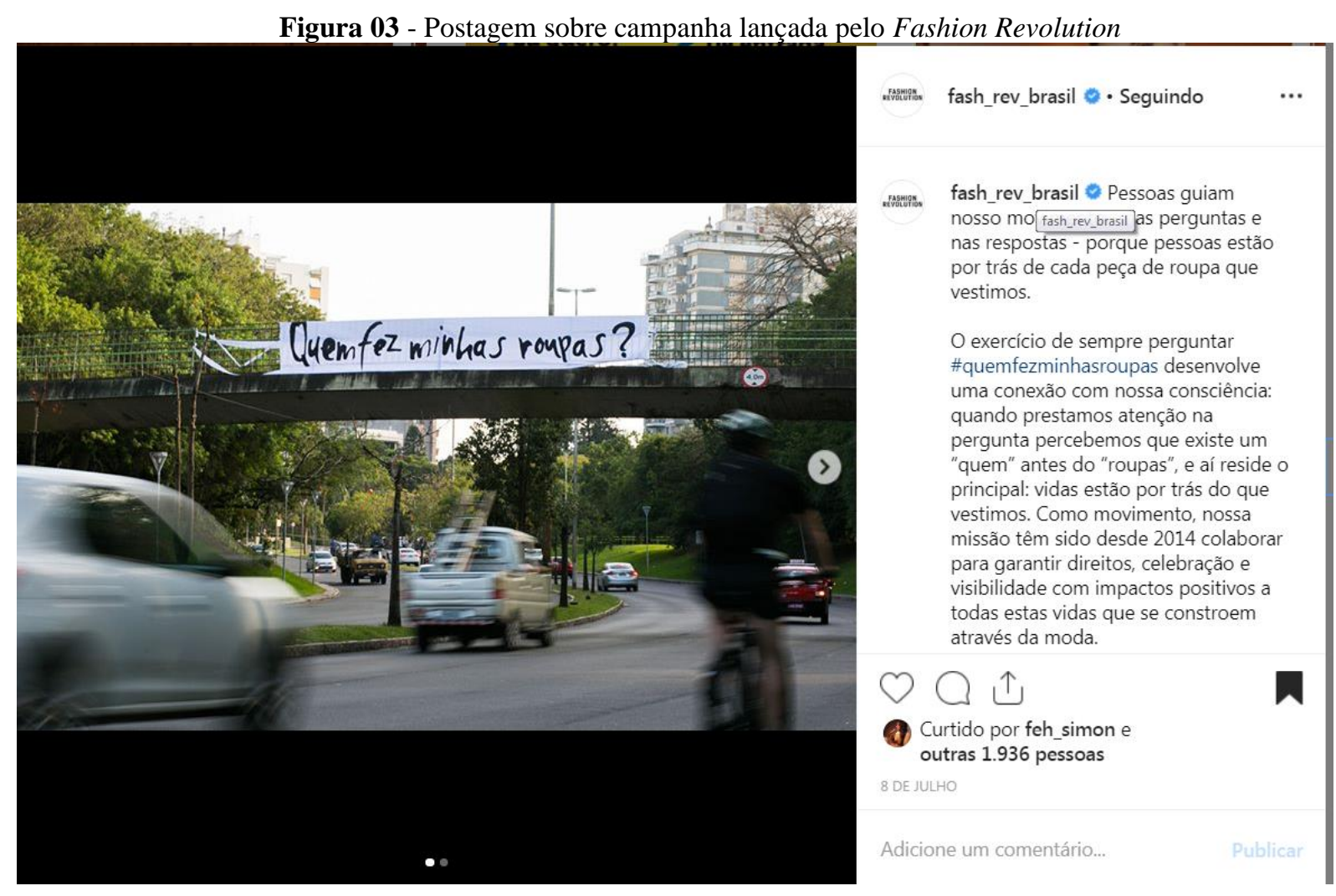

(Fonte: Instagram - Perfil Fashion Revolution Brasil)

Também a convergência entre a preocupação com os trabalhadores da indústria da moda, por vezes submetidos a condições de trabalho extremas, e o inquietante impacto ambiental da cadeia de produção têxtil, ambos geralmente localizados em países em desenvolvimento, estão no âmago do movimento Fashion Revolution. Desse modo, a promoção do ambientalismo pode impactar a sociedade não apenas local, como a global, em busca de justiça social e ambiental. 
Em Bangladesh, por exemplo, desde o desastre do Rana Plaza, os trabalhadores do vestuário estão em campanha por salários dignos. Contudo, conforme o Consórcio de Direito dos Trabalhadores, há repressão, ataques violentos e intimidação dos trabalhadores. Os trabalhadores do vestuário em Bangladesh pedem aumento desde que aumentou o salário mínimo no país em novembro de 2018 para 22 dólares por semana (THE GARDIAN, 2019).

No Brasil, noticiou-se em 30 de janeiro de 2019 que: "Em Carapicuíba, na Grande São Paulo, 33 bolivianos foram resgatados vivendo em condições precárias e costurando por R $\$ 1 \mathrm{a}$ peça" (SIMON, 2019).

Esse cenário fomenta as campanhas do movimento Fashion Revolution nas redes sociais e nas demais mídias de massa, com o objetivo de mostrar para a sociedade de consumo as consequências dos seus hábitos de consumo não apenas para o meio ambiente, mas, também para os trabalhadores da indústria da moda.

Figura 04 - Postagem sobre campanha lançada pelo Fashion Revolution

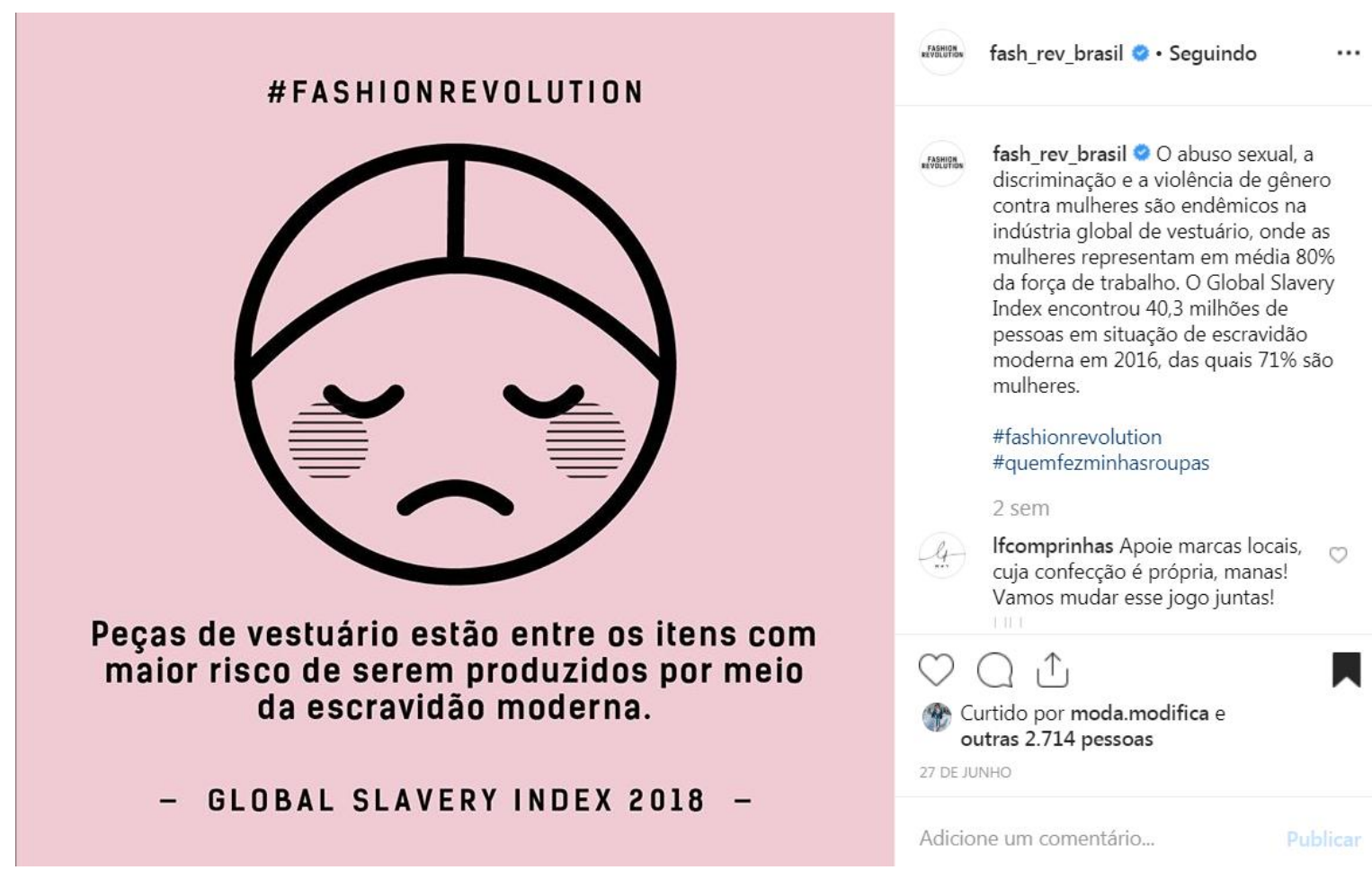

(Fonte: Instagram - Perfil Fashion Revolution Brasil)

Ainda, segundo Manuel Castells, o movimento ambientalista se caracteriza pela introdução de uma nova temporalidade, na qual a relação entre o homem e a natureza seja um processo de evolução a longo prazo (CASTELLS, 2018). Assim, o movimento Fashion Revolution ao lançar a 
campanhas em que se fomenta o debate de formas de inserção de sustentabilidade no sistema de moda com respeito ao meio ambiente e gerações futuras, promoção da proteção aos trabalhadores da indústria da moda em toda a cadeia de produção, introduz essa nova temporalidade.

Desse modo, verifica-se que o Fashion Revolution atende as características determinantes de movimento social, eis que possui a) Identidade: cidadãos preocupados com os impactos ambientais da indústria da moda; b) Adversário: exploração na indústria da moda; c) Objetivo: transparência na indústria da moda (CASTELLS, 2018).

A caracterização do movimento Fashion Revolution como movimento ambientalista de justiça ambiental e social pode ser de extrema relevância para uma mudança efetiva na indústria da moda, tendo em vista o alcance e representatividade da sua mobilização. A promoção da transparência na indústria da moda pode ser uma contracultura importante em um contexto de uma sociedade de consumo, a observância ao direito ao ambiente ecologicamente equilibrado.

\section{CONSIDERAÇÕES FINAIS}

Não há dúvidas de que o movimento Fashion Revolution pode ser indicado como um movimento ambientalista de justiça ambiental e social. O engajamento do movimento pela inserção de sustentabilidade na indústria da moda e a promoção da transparência na cadeia de produção, como por exemplo o movimento \#quemfezminhasroupas, transformam a sociedade cada vez mais atenta aos impactos causados pelo consumo desenfreado.

As características do movimento Fashion Revolution como movimento ambientalista de justiça ambiental são latentes e, mesmo sendo um movimento considerado recente, suas ações são significativas. Com efeito, a promoção da transparência na indústria da moda se relaciona também a propagar conhecimento e, consequentemente, inserir sustentabilidade na cadeia de produção e melhorias nas condições de trabalho, o que promove o direito ao ambiente ecologicamente equilibrado em relação ao aspecto social de justiça ambiental.

Em oposição ao modo de consumo da sociedade atual, a atuação de um movimento de justiça ambiental e social que estimula o consumo sustentável através da escolha de produtos que utilizam menos recursos naturais em sua produção, garantem direitos trabalhistas aos que os produzem, permitem o reaproveitamento ou reciclagem, bem como mostra ao consumidor que as 
suas escolhas de compras terão consequências ambientais e sociais é fundamental para adoção de práticas de consumo sustentável pode promover uma contracultura pela transparência na indústria da moda.

Ainda, a partir do movimento Fashion Revolution tem-se que preocupação com sustentabilidade em toda a cadeia de produção têxtil deve transcender aos desejos dos consumidores e os interesses de mercado. Trata-se, em realidade, de uma nova finalidade para sociedade consumo com a promoção de um ambiente ecologicamente equilibrado frente a atual crise ambiental.

\section{REFERÊNCIAS}

ABREU, Nathália. O movimento que inspira a Moda Sustentável - Conheça o Fashion Revolution. Autossustentável. Disponível em: http://autossustentavel.com/2019/05/omovimento-que-inspira-a-moda-sustentavel-conheca-o-fashion-revolution.html. Acesso em: 17 jul. 2019

ACSELRAD, Henri; MELLO, Cecilia Campello do Amaral; BEZERRA, Gustavo das Neves. O que é Justiça Ambiental. Rio de Janeiro: Garamond, 2009

ARAUJO, Luiz Ernani Bonesso de; TYBUSCH, Jerônimo Siqueira. Biodiversidade na América Latina: ecologia política e a regulação jurídico ambiental. In.; Justiça Y Medio Ambiente. Espanã: Punto Rojo Libros, 2013.

BAUDRILLARD, Jean. Sociedade de consumo. - Reimp. - (Arte \& Comunicação). Lisboa: EDIÇÕES 70 LTDA., 2018.

BEZERRA, Fabiano Cezar Petrovich. O Meio Ambiente na Constituição Federal de 1988: Um olhar sobre os Princípios Constitucionais Ambientais. In.: Revista Eletrônica Constituição e Garantia de Direitos. Ano I, vol.2, 2013. Disponível em: https://periodicos.ufrn.ber/constituicaoegarantiadedireitos/artiche/view/4275 Acesso em: 10 de out. 2019.

BLANCHARD, Tamsin. Who made my clothes? Stand up for workers' rights with Fashion Revolution week. The Gardian. Disponível em: https://www.theguardian.com/fashion/commentisfree/2019/apr/22/who-made-my-clothes-standup-for-workers-rights-with-fashion-revolution-week. Acesso em: 17 jul. 2019.

BRASIL. Constituição Federal de 1988. Brasília, 1988. Disponível em: http://www.planalto.gov.br/ccivil_03/constituicao/constituicaocompilado.htm. Acesso em: 07 out. 2019. 
CALEIRO, João Pedro. 5 anos após desabamento, o que mudou nas fábricas de Bangladesh? Revista Exame. Disponível em: https://exame.abril.com.br/economia/5-anos-apos-desabamentoo-que-mudou-nas-fabricas-de-bangladesh/. Acesso em: 24 jun. 2019.

CASTELLS, Manuel. O poder da Comunicação. Trad. Vera Lúcis Mello Joscelyne; rev. da trad. Isabela Machado de Oliveira Fraga. 1ª Ed. São Paulo/Rio de Janeiro: Paz e Terra, 2015.

CASTELLS, Manuel. O poder da identidade (A era da informação: economia, sociedade e cultura, v.2). Trad. Klauss Brandini Gerhardt. São Paulo: Editora Paz e Terra, 2018.

CONGA, James. Making Climate Change Fashionable - The Garment Industry Takes On Global Warming. Forbes. Disponível em:

https://www.forbes.com/sites/jamesconca/2015/12/03/making-climate-change-fashionable-thegarment-industry-takes-on-global-warming/\#58bb127679e4. Acesso em 26 mai. 2019.

ECYCLE. O que é fast fashion? Disponível em: https://www.ecycle.com.br/5891-fast-fashion. Acesso em 26 mai. 2019.

FASHION Revolution. About us. Disponível em: https://www.fashionrevolution.org/about/. Acesso em 24 jun. 2019

MATTOS, Ana Letícia. FASHION Revolution - Entenda o movimento! Blog Anita Bem Criada. Disponível em: http://anitabemcriada.com/2018/05/02/fashion-revolution-entenda-omovimento/. Acesso em: 17 jul. 2019.

FOLADORI, Guillermo. Avanços e limites da sustentabilidade social. Disponível em http://www.ipardes.pr.gov.br/ojs/index.php/revistaparanaense/article/view/214. Acesso em: 07 out. 2019.

INSTAGRAM. Fashion Revolution Brasil. Instagram, Brasil. Disponível em: https://www.instagram.com/fash_rev_brasil/ Acesso em: 18 jul. 2019.

LIPOVETSKY, Gilles. A era do vazio. São Paulo: Companhia das Letras, 2005.

LEGNAIOLI, Stella. O que é fast fashion? ECYCLE. Disponível em: https://www.ecycle.com.br/5891-fast-fashion. Acesso em 26 mai. 2019.

OLIVEIRA, Thaynara Rezende de. Fashion Revolution: o movimento que está transformando a moda. Slowly. Disponível em: https://slowly.com.br/fashion-revolution/ Acesso em: 17 jul. 2019.

PRIBERAM. Dicionário Priberam da Língua Portuguesa. Disponível em: https://dicionario.priberam.org/fait\%20divers. Acesso em: 01jun. 2019.

SEN, Amartya. Uma ideia de justiça. Traduzido por Denise Bottmann e Ricardo Doninelli Mendes. São Paulo: Companhia das Letras, 2011. 
SIMON, Fernanda. Bolivianos resgatados na Grande São Paulo costurando por R \$ 1 a peça reforçam a mensagem que ainda há muito o que se fazer. Carta Capital. Disponível em: https://www.cartacapital.com.br/blogs/fashion-revolution/ainda-ha-escravos-por-tras-das-roupas/. Acesso em: 7 out. 2019.

\title{
FASHION REVOLUTION AS ENVIRONMENTAL MOVEMENT OF
}

\section{ENVIRONMENTAL JUSTICE: AN ANALYSIS UNDER THE ECONOMICALLY BALANCED ENVIRONMENTAL OPTICS}

\begin{abstract}
This study aims to analyze the possibility of identifying the Fashion Revolution movement as an environmental movement of environmental and social justice. Thus, we seek to present and characterize the environmentalist movements of environmental and social justice, in view of the right to an ecologically balanced environment. Also, the possibility of identifying the Fashion Revolution movement as an environmental movement of environmental and social justice is analyzed, and thus a counterculture generator also in the fashion industry. As a basic theory, the pragmatic-systemic epistemological matrix will be used, which allows an interdisciplinary approach about the characterization of the Fashion Revolution movement as an environmental movement of environmental and social justice, based on the analysis of the main characteristics and themes of environmental movements. With the present study it was possible to conclude that the Fashion Revolution movement can be indicated as an environmental movement of environmental and social justice, according to the characteristics and main themes of the environmental movement
\end{abstract}

Keywords: Environmental movement. Justice. Fashion Revolution. Right. Balanced environment. 